\title{
Checking of Radially Sawn Scots Pine and Norway Spruce Wood
}

\author{
Martti Venäläinen'1, Yonggang Hu르, Erkki Verkasalo ${ }^{3}$ \\ ${ }^{1}$ Natural Resources Institute Finland (Luke), Punkaharju, Finland \\ ${ }^{2}$ School of Forest Sciences, Wood Material Science, University of Eastern Finland, Joensuu, Finland \\ ${ }^{3}$ Natural Resources Institute Finland (Luke), Joensuu, Finland \\ Email: martti.venalainen@luke.fi
}

How to cite this paper: Venäläinen, M., Hu, Y. and Verkasalo, E. (2016) Checking of Radially Sawn Scots Pine and Norway Spruce Wood. Natural Resources, 7, 505-514. http://dx.doi.org/10.4236/nr.2016.79043

Received: August 9, 2016

Accepted: September 6, 2016

Published: September 9, 2016

Copyright $\odot 2016$ by authors and Scientific Research Publishing Inc. This work is licensed under the Creative Commons Attribution International License (CC BY 4.0).

http://creativecommons.org/licenses/by/4.0/ (c) (i) Open Access

\begin{abstract}
In exterior use, wood is subjected to weathering that causes checking and other deterioration in the appearance and technical properties. We studied quantitatively the surface checking of radially and tangentially sawn specimens of Scots pine (Pinus sylvestris L.) and Norway spruce (Picea abies Karst.) wood in a cyclic climate chamber test. The results strongly suggested that the sawing direction determines the checking performance of both Scots pine and Norway spruce wood. The radial surface of Scots pine specimens had 62\% less checks than the tangential one, and the cumulative area of checks was $74 \%$ smaller. For Norway spruce, the respective figures were: $83 \%$ less in the check number and $91 \%$ less in the check area. Different from pine, in spruce specimens the checks of radial surface were significantly smaller. Thus, spruce timber gained clearly more about radial sawing pattern. The effect of annual ring width was similar for pine and spruce: the reduction in annual growth worsened the checking. The increase in density worsened the checking of spruce but did not change the performance of pine. In pine wood, the increase of heartwood proportion reduced the fluctuation of moisture content and the formation of checks.
\end{abstract}

\section{Keywords}

Scots Pine, Norway Spruce, Checking, Sawing Pattern, Moisture Content, Weathering

\section{Introduction}

Checking of wood surface is an undesired phenomenon that shortens the aesthetic and technical service life of wooden constructions [1]. Checking may lead to an excessive need of maintenance, and can be the cause for choosing other materials instead of 
wood in the end-uses subjected to checking. Checking takes place during the drying of timber, as a result of internal stresses that arise from anisotropic shrinkage or irregularities in wood, when the moisture content (MC) decreases under the fiber saturation point (FSP) (e.g. [2] [3]). In the exterior use, checking is one visible element of weathering, the gradual degradation of wood due to solar radiation, fluctuating moisture and temperature, and microorganisms (e.g. [1] and references therein, [4]). Paints and other coatings are used to protect wood from weathering processes [1]. In Nordic countries, both Norway spruce (Picea abies Karst.) and Scots pine (Pinus sylvestris L.) are used widely in outdoor applications, such as cladding, decking, window frames, sashes and shutters and outside furniture. In wooden facades, Norway spruce is used in most cases due to its low permeability and Scots pine occasionally because of its durable heartwood (e.g. [5] [6]).

Due to the anisotropy, tangential surfaces shrink more than radial ones during drying. Consequently, one suggested solution to minimize checking has been the setting of sawing direction of timber so that the proportion of radial surfaces is maximized compared to tangential surfaces [7]. Sandberg and Söderström [8] carried out an experiment in which the check formation of radially and tangentially sawn Scots pine and Norway spruce was followed in outdoor conditions for several years. Besides the works of Sandberg [9] [10] and Sandberg and Söderström [8] there are not any quantitative studies available on potential benefits of radial sawing as regards the checking of pine or spruce timber.

Besides the effect on moisture dynamics and checking tendency, there are also other purposes to optimize the sawing pattern between tangential and radial, such as visual outlook (grain pattern, knot structure), surface hardness, and performance in gluing and in surface and pressure treatments [11] [12]. On the other hand, the sawing pattern has effect on volumetric and value yield, time expenditure and costs in the sawing process that are of high importance for the saw mill [6] [7] [13] [14].

The aim of this research was to study quantitatively the checking of tangentially and radially sawn wood of Scots pine and Norway spruce in a cyclic climate chamber test. Furthermore, the aim was to find correlations between the checking performance and basic wood quality characteristics. The main emphasis was put on Scots pine wood while Norway spruce wood was used as a reference material.

\section{Materials and Methods}

\subsection{Sample Preparation}

Logs of trees from mature-to-final-cut stands in Finland and Sweden were employed for the study. Scots pines were from five regions (Southern Sweden, Northern Finland, Central Finland, South-Central Sweden and South-Eastern Finland) and Norway spruces from two regions (South-Eastern and Western Finland). The Scots pine materials have been described in detail in [15] and Norway spruce materials in [16]. The sampling height of logs in a tree was $0-2 \mathrm{~m}$. The logs were sawn to boards and selected boards were planed and cut to wood specimens of $17 \times 50 \times 100 \mathrm{~mm}$ (dimensions as 
fresh), aiming the $15 \mathrm{~cm}^{2}$ sized surfaces to be either tangential or radial. The longitudinal length was always $100 \mathrm{~mm}$. The total number of specimens was 228 (Table 1). The specimens were conditioned at Metla Research Center in Joensuu, Finland, at 65\% $\mathrm{RH}$ and $20^{\circ} \mathrm{C}$ to about $12 \% \mathrm{MC}$, after which they were weighed and their dimensions were measured by caliper to calculate the exact volume. The data were used to determine the specific gravity (SG) of conditioned specimens using Equation (1) and Equation (2):

$$
\rho_{12}=\frac{A D W}{L \times T \times W}
$$

where: $A D W=$ air-dry weight, $\mathrm{g}($ at $12 \% \mathrm{MC}) ; L, T, W=$ dimensions, $\mathrm{cm}($ at $12 \% \mathrm{MC})$;

$$
S G=\frac{\rho_{12}}{\rho_{\mathrm{H}_{2} \mathrm{O}}}
$$

where: $\rho_{12}=$ air-dry density of specimen; $\rho_{\mathrm{H}_{2} \mathrm{O}}=$ density of water.

Then, the cross-cut ends of the specimens were sealed with lacquer to prevent the longitudinal water sorption in the climate chamber test.

\subsection{Climate Chamber Test}

The conditioned specimens were exposed to a climate chamber test at Stora Enso Research Center in Imatra, Finland. The weathering cycle included water sprinkling (20 $\mathrm{min}$ ), a lag (30 $\mathrm{min})$, and drying under ultraviolet-infrared (UV-IR) radiation together with ventilation $(130 \mathrm{~min})$. The surface temperature of the specimens was expected to reach $60^{\circ} \mathrm{C}$ during the drying phase. The weathering cycle was repeated four times. The duration of the steps and the sufficient number of cycles were concluded according to [17] and a pilot test.

\subsection{Annual Ring Number and Ring Angle}

The cross-cut ends of the specimens were photographed after the climate chamber test (Figure 1). The images were used to determine the true annual ring direction of the exposed surface since the surfaces were seldom exactly radial or tangential. The tangent

Table 1. The materials used in the study. Means (sd in parenthesis) are presented for the basic wood characteristics. The determination of annual ring variables is presented in Figure 1.

\begin{tabular}{ccccc}
\hline & \multicolumn{2}{c}{ Scots pine } & \multicolumn{2}{c}{ Norway spruce } \\
\cline { 2 - 5 } & \multicolumn{2}{c}{ Surface } & \multicolumn{2}{c}{ Surface } \\
\cline { 2 - 5 } & Tangential & Radial & Tangential & Radial \\
\hline Number of specimens & 82 & 84 & 31 & 31 \\
Specific gravity (SG) & $0.603(0.073)$ & $0.621(0.074)$ & $0.452(0.060)$ & $0.448(0.046)$ \\
Annual rings/17 mm & $15.3(9.0)$ & $12.7(7.2)$ & $7.6(3.0)$ & $7.3(3.5)$ \\
Ring angle, & $13(11)$ & $84(14)$ & $2(2)$ & $79(11)$ \\
Heartwood proportion, \% & $50(46)$ & $72(39)$ & Not determined & Not determined
\end{tabular}


line of annual rings was drawn first and then the vertical line of this tangent line. The angle between the vertical line of the specimen surface and the vertical line of the tangent line was used as a quantitative variable for the annual ring orientation. This variable, called ring angle in this article, told how close the exposed surface was compared to exactly radial (ring angle $90^{\circ}$ ) or tangential $\left(0^{\circ}\right)$ surface (Table 1 ). The number of annual rings was counted for $17 \mathrm{~mm}$ section of the vertical of the tangent line.

\subsection{Moisture Content Change and Heartwood Percentage}

The specimens were weighed during the $4^{\text {th }}$ weathering cycle before and after the last drying phase to determine the change in MC. The specimens were afterwards ovendried at $103^{\circ} \mathrm{C} \pm 2{ }^{\circ} \mathrm{C}$ for $24 \mathrm{~h}$ and weighed to get the dry mass that was used to calculate the MC. Finally, the Scots pine specimens were cross-cut and one lacquer-free end was stained with sulfanilic acid to determine the borderline between heartwood and sapwood. The heartwood proportion of Scots pine specimens was determined as a percentage of the stained cross-cut area.

\subsection{Measuring of Checks and Statistical Analysis}

High resolution digital images of the dry exposed specimen surfaces were examined using Image-Pro Plus 4.5 software (Figure 2). The darker color of checks determined the objects to be analyzed by the software. The number of objects as well as the true area, length and width of each object were recorded. Only the objects greater than 1.5 $\mathrm{mm}$ in length were included in order to avoid other small dark-colored spots, such as resin ducts, to be recorded as checks.

One-way analysis of variance was used to test the effect of sawing direction on the number of checks, the total area of checks, and the size of checks. The non-parametric Spearman rank order correlation analysis was used to investigate the relationships between the variables measured from the specimens.

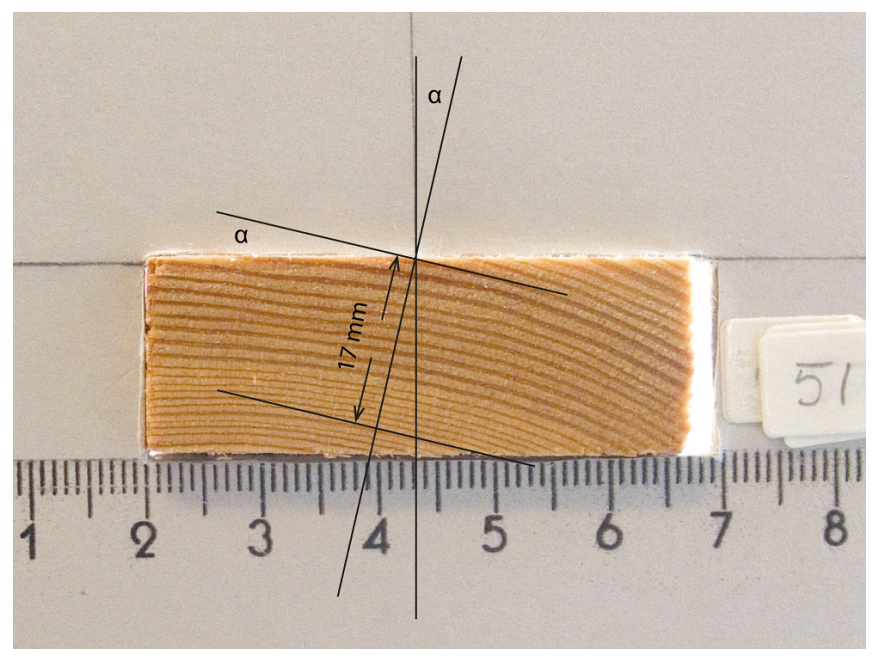

Figure 1. Determination of the number of annual rings per $17 \mathrm{~mm}$ of radius and the orientation of annual rings, called ring angle $(\alpha)$, on the exposed surface of sample. 

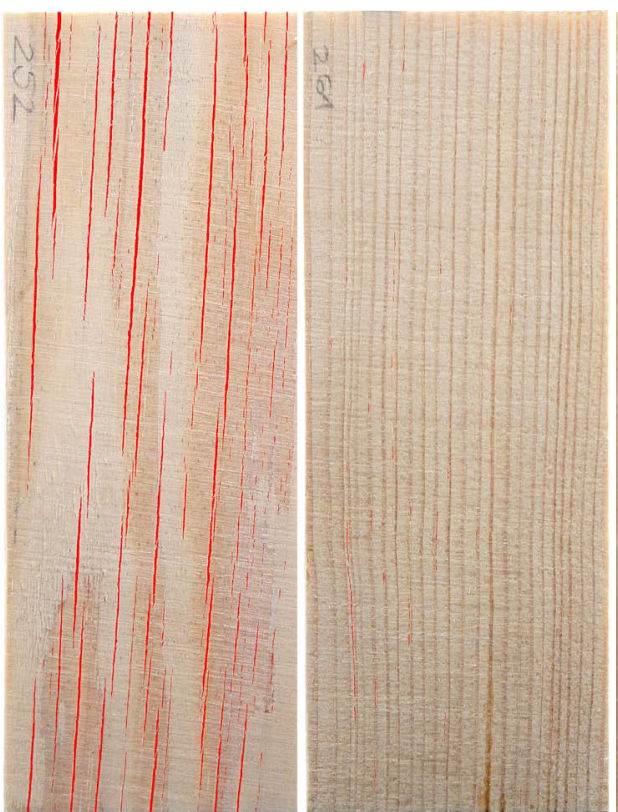

357

292

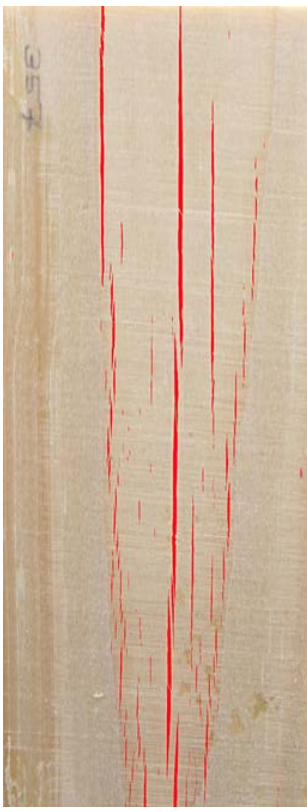

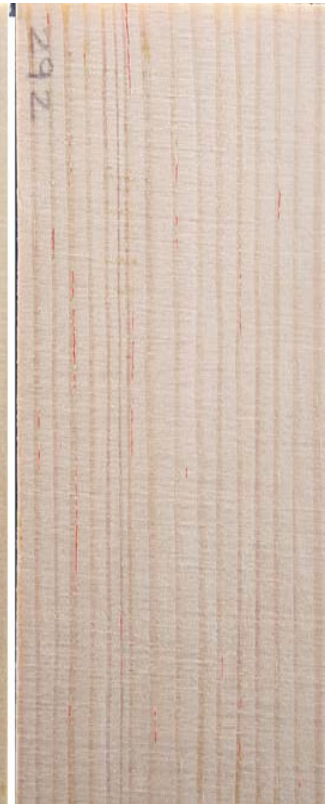

Figure 2. Example of images used to study quantitatively the checking performance of tangentially and radially sawn Scots pine (252 tan., 261 rad.) and Norway spruce (357 tan., 292 rad.) timber. Clusters of dark colored pixels interpreted to be checks were turned red to enhance the contrast. The number of checks was counted and dimensions of each check were analyzed by Image-Pro Plus 4.5 software.

\section{Results and Discussion}

According to the results of our climate chamber test, the tangential surfaces of both Scots pine and Norway spruce specimens were significantly more prone to checking than the radial ones (Tables 2-4). On average, the checking of pine was clearly more severe than that of spruce, as regards the number of checks and the total area of checks (Table 2). In pine wood tangential surfaces, the number of checks was 2.6 fold ( $\mathrm{p}<$ $0.000)$ and the total area of checks was 3.9 fold $(\mathrm{p}<0.000)$ compared to radial surfaces while in the average size of checks there was no significant difference $(\mathrm{p}=0.103)$. In spruce wood, the respective figures were 6.2 fold $(\mathrm{p}<0.000)$ and 11 fold $(\mathrm{p}<0.000)$ in tangential surfaces compared with radial surfaces. In contrast to pine, in spruce the difference in the average size of checks was significant between the sawing directions ( $p=$ 0.002). The checks of tangential surfaces were 4.5 fold in size.

The MC change was calculated for the gross dry mass of the specimens and it appeared to be fairly small. Presumably during the test cycle, the MC change in the surface layer of the specimens was much bigger than the given gross values and $\mathrm{MC}$ of the surface layer exceeded FSP. In Scots pine, the MC change of tangential surfaces was bigger than that of radial ones. The sawing direction had no effect on the MC change in spruce. The average MC of spruce samples remained on a lower level (19\% - 13\% vs $28 \%-18 \%$ ) during the weathering treatment, however the MC change was nearly equal (5.3\% units vs $5.3 \%-7.7 \%$ units) in spruce and pine wood (Table 2 ). 
Table 2. Moisture content (MC) and checking performance of radially and tangentially sawn Scots pine and Norway spruce wood in a climate chamber test. The figures are means (sd in parenthesis) of $17 \times 50 \times 100 \mathrm{~mm}$ sized specimens for $\mathrm{MC}$ and $15 \mathrm{~cm}^{2}$ sized exposed surfaces for checking variables.

\begin{tabular}{ccccc}
\hline & \multicolumn{2}{c}{ Scots pine } & \multicolumn{2}{c}{ Norway spruce } \\
\cline { 2 - 5 } & \multicolumn{2}{c}{ Surface } & \multicolumn{2}{c}{ Surface } \\
\cline { 2 - 5 } & Tangential & Radial & Tangential & Radial \\
\hline MC after sprinkling, \% & $28(13)$ & $23(11)$ & $19(5)$ & $18(2)$ \\
MC after drying, \% & $21(8)$ & $18(8)$ & $14(3)$ & $13(1)$ \\
MC change, \%-units & $7.7(5.5)$ & $5.3(3.5)$ & $5.3(1.2)$ & $5.3(1.1)$ \\
Number of checks $(>1.5 \mathrm{~mm})$ & $58(45)$ & $22(25)$ & $23(27)$ & $3.7(7)$ \\
Total area of checks, mm & $43(45)$ & $11(24)$ & $32(35)$ & $2.8(6)$ \\
Length sum of checks, mm & $248(201)$ & $67(81)$ & $111(118)$ & $17(32)$ \\
Width sum of checks, mm & $9.1(7.9)$ & $2.7(3.3)$ & $5.2(5.8)$ & $0.53(1.0)$ \\
Mean area of check, mm ${ }^{2}$ & $0.70(0.56)$ & $0.48(1.06)$ & $1.6(1.95)$ & $0.35(0.70)$ \\
\hline
\end{tabular}

Table 3. Spearman rank order correlation analysis for the explanatory variables and the checking performance of Scots pine wood (the correlation coefficient and p-value in parenthesis) $(n=168)$.

\begin{tabular}{cccccc}
\hline & \multicolumn{5}{c}{ Checking variable } \\
\cline { 2 - 5 } & Number & Total area & Length sum & Width sum & Mean area \\
\hline MC change & 0.211 & 0.212 & 0.227 & 0.207 & 0.156 \\
Specific gravity (SG) & $0.006)$ & $(0.006)$ & $(0.003)$ & $(0.007)$ & $(0.044)$ \\
& 0.118 & 0.099 & 0.097 & 0.112 & 0.088 \\
Number of rings & $(0.127)$ & $(0.202)$ & $(0.210)$ & $(0.146)$ & $(0.259)$ \\
& 0.157 & 0.199 & 0.198 & 0.138 & 0.230 \\
Ring angle & $(0.043)$ & $(0.010)$ & $(0.010)$ & $(0.074)$ & $(0.003)$ \\
& -0.448 & -0.464 & -0.474 & -0.472 & -0.387 \\
Heartwood \% & $(<0.001)$ & $(<0.001)$ & $(<0.001)$ & $(<0.001)$ & $(<0.001)$ \\
& -0.186 & -0.221 & -0.226 & -0.186 & -0.164 \\
& $(0.017)$ & $(0.005)$ & $(0.004)$ & $(0.017)$ & $(0.036)$ \\
\hline
\end{tabular}

Our material was not optimal for comparing the performance of the two tree species regarding the effects of ring orientation, since the growth rate of the sampled pine and spruce trees was not equal. All pines were fairly slowly growing, the average annual increment of radius being only $1.2 \mathrm{~mm}$. By contrast, very slowly growing spruces were missing from the material set and the average annual increment of radius was $2.3 \mathrm{~mm}$. Thus the generalization of the differences between species needs to be done cautiously.

The results of Spearman rank order correlation analysis are presented in four groups: the correlation coefficients among the explanatory variables for pine (Table 5) and spruce 
Table 4. Spearman rank order correlation analysis for the explanatory variables and the checking performance of Norway spruce: the correlation coefficient and the probability (in parenthesis) $(n=60)$.

\begin{tabular}{cccccc}
\hline & \multicolumn{5}{c}{ Checking variable } \\
\cline { 2 - 6 } & Number & Total area & Length sum & Width sum & Mean area \\
\hline MC change & -0.432 & -0.387 & -0.420 & -0.409 & -0.351 \\
& $(0.001)$ & $(0.002)$ & $(0.001)$ & $(0.001)$ & $(0.006)$ \\
Specific gravity (SG) & 0.402 & 0.380 & 0.404 & 0.396 & 0.283 \\
& $(0.002)$ & $(0.003)$ & $(0.001)$ & $(0.002)$ & $(0.029)$ \\
Number of rings & 0.469 & 0.419 & 0.472 & 0.423 & 0.318 \\
& $(0.001)$ & $(0.001)$ & $(0.001)$ & $(0.001)$ & $(0.013)$ \\
Ring angle & -0.476 & -0.503 & -0.490 & -0.507 & -0.439 \\
& $(0.001)$ & $(<0.001)$ & $(<0.001)$ & $(<0.001)$ & $(0.001)$ \\
\hline
\end{tabular}

Table 5. Spearman rank order correlation analysis for the Scots pine wood variables that were used to explain the checking performance (the correlation coefficient, and the p-value in parenthesis $)(n=168)$.

\begin{tabular}{ccccc}
\hline & Specific gravity (SG) & Number of rings & Ring angle & Heartwood \% \\
\hline Number of rings & -0.024 & & & \\
& $(0.755)$ & & & \\
Ring angle & -0.001 & -0.191 & & \\
& $(0.992)$ & $(0.013)$ & 0.198 & \\
Heartwood \% & 0.052 & -0.060 & $(0.011)$ & -0.851 \\
MC change & $(0.507)$ & $(0.448)$ & -0.205 & $(<0.001)$ \\
\hline
\end{tabular}

(Table 6), and the coefficients between the explanatory variables and checking performance for pine (Table 3 ) and for spruce (Table 4). In the correlation analysis, the ring angle was used as a quantitative measure for the surface orientation. Specimens with tangential orientation had values close to $0^{\circ}$ and the ones with radial orientation values close to $90^{\circ}$.

In pine wood, there was a strong negative correlation between the heartwood percentage and the MC change indicating heartwood to be slower than sapwood to adsorb water (Table 5). Furthermore, there was a weak but significant negative correlation between the SG and MC change indicating heavier wood to be slower to reach FSP. Interestingly, SG and number of annual rings did not correlate which indicates that slowly growing pines did not produce heavier wood. The slight negative correlation between ring angle and $\mathrm{MC}$ change suggested that radially sawn surfaces were less absorbent.

The correlation coefficients for ring angle, as well as the means in Table 1, showed 
Table 6. Spearman rank order correlation analysis for the wood properties that were used as explanatory variables of Norway spruce: the correlation coefficient and the probability (in parenthesis) $(\mathrm{n}=60)$.

\begin{tabular}{cccc}
\hline & Specific gravity $(\mathrm{SG})$ & Number of rings & Ring angle \\
\hline Number of rings & 0.687 & & \\
& $(<0.0001)$ & & \\
Ring angle & -0.078 & -0.167 & \\
& $(0.555)$ & $(0.202)$ & 0.086 \\
MC change & -0.617 & -0.590 & $(0.512)$ \\
\hline
\end{tabular}

that the two sawing directions were not similar as regards the number of rings and heartwood percentage. Radially sawn samples had slightly less annual rings but more heartwood compared to tangentially sawn ones. This was primarily due to the fact that the radial surfaces were obtained closer to the pith and the tangential surfaces closer to the surface of a log. The difference in the heartwood percentage, rather than the sawing direction as such, might be the reason for the slight negative correlation between ring angle and $\mathrm{MC}$ change.

The ring angle had the strongest and most significant correlation with the variables measuring the quantity and size of checks (Table 2). The negative coefficient value indicated, consistently with the means in Table 3, that radially sawn surfaces were less prone to checking. As regards the role of other explanatory variables, the bigger the MC change the more there was check formation. On the other hand, a bigger proportion of less absorbent heartwood reduced the checking. SG did not correlate with checking but, interestingly, very narrow annual rings enlarged the size of checks.

In contrast to pine, in spruce wood the number of annual rings and SG had a strong positive correlation indicating that slow growth of spruces leads to heavy wood (Table 6). Furthermore, slowly growing heavy wood seemed to be significantly slower to absorb water.

The correlation coefficients between the ring angle and checking variables indicated that also in spruce the surface orientation is an important factor to determine the checking performance (Table 4). In addition, the other explanatory variables had more significant role than in the case of pine. In spruce wood, more clearly than in pine, slower growth led significantly to more severe checking. Different from pine, in spruce wood higher SG led significantly to more severe checking. Surprisingly, also decreasing MC change seemed to be associated with more severe checking. The negative correlation coefficient is confusing since such causality is irrational. Our explanation is that increasing SG which worsens checking has so strong impact on the MC change that this strong correlation covers the effect of MC change on checking.

Our results about the significant effect of the surface orientation on the checking performance of pine and spruce wood were in accordance with the results of Sandberg and Söderström [8] who concluded that after a long-term outdoor exposure "the an- 
nual ring orientation was the most important factor affecting crack development on weathering". Furthermore, the results supported the recommendations to use radial sawing pattern to reduce checking given by Sandberg [7]. However, Sandberg stresses in [10] that, regardless the sawing pattern, the wood close to pith is always prone to checks and distortions and should thus be avoided. According to our quantitative measure of the surface orientation, i.e. ring angle, most of our observations were close to $0^{\circ}$ (tangential orientation) or $90^{\circ}$ (radial orientation), especially as regards the distribution of spruce specimens, while the observations in the middle of the extreme values were few. Thus our data does not enable any regression analysis to find out what is the critical annual ring orientation for radial surface to gain the low level checking performance.

The anisotropy of solid wood is a well-known phenomenon, i.e. the dimensional changes are not similar to tangential, radial, and longitudinal directions when the MC change is causing swelling or shrinking. The internal tensions due to fast drying shrinkage and anisotropy are considered to be the ultimate reason for the checking of wood. Although the reasons to the anisotropic behavior of wood are not fully understood (see e.g. [8] and [9]) the unwanted consequences of anisotropy can be reduced by managing the sawing direction.

In exterior uses wood is exposed to weathering and therefore wood defects like checks threaten to shorten the service life of e.g. wooden façade, decking, windows or outdoor furniture, and anyway increase the need of maintenance. Based on our results we conclude that when Scots pine is used as a raw material for cladding and exterior-use products, utilizing radial sawing pattern and using heartwood seem to be efficient ways to reduce surface checking. In contrast, the use of very slowly growing or higher-density wood does not improve the checking performance of pine. Norway spruce timber that is generally less prone to checking gains even more than pine from the radial sawing pattern since it reduces the number of checks close to zero and reduces the size of the few checks. The use of slowly grown and dense spruce wood should be avoided because such wood seems to be more prone for checking.

\section{Acknowledgements}

The authors are grateful to Ms. Paula Machon for carrying out the pilot study and for developing the quantitative check analysis procedure based on Image-Pro Plus software, Ms. Eija Matikainen for carrying out the photographing and the image analysis of the materials, Mr. Janne Manninen and Mr. Janne Pynnönen for the possibility to use Stora Enso research facility at Imatra, and Mr. Mika Kankkunen for carrying out the climate chamber test there.

\section{References}

[1] Feist, W.C. (1990) Outdoor Wood Weathering and Protection. In: Rowell, R.M. and Barbour, R.J., Eds., Archaeological Wood: Properties, Chemistry, and Preservation, Advances in Chemistry Series 225, American Chemical Society, Washington DC, 263-298.

http://dx.doi.org/10.1021/ba-1990-0225.ch011 
[2] Panshin, A.J. and de Zeeuw, C. (1980) Textbook of Wood Technology. 4th Edition, McGraw-Hill, Inc., New York.

[3] Gerhards, C.C. (1982) Effect of Moisture Content and Temperature on the Mechanical Properties of Wood: An Analysis of Immediate Effects. Wood and Fiber Science, 14, 4-36.

[4] Evans, P.D., Urban, K. and Chowdhury, M.J.A. (2008) Surface Checking of Wood Is Increased by Photodegradation Caused by Ultraviolet and Visible Light. Wood Science and Technology, 42, 251-265. http://dx.doi.org/10.1007/s00226-007-0175-0

[5] Meyer, R.W. and Kellogg, R.M. (1982) Structural Uses of Wood in Adverse Environments. Van Nostrand Reinhold Company, New York.

[6] Kärkkäinen, M. (2007) Puun rakenne ja ominaisuudet (Wood Structure and Properties, in Finnish). Metsäkustannus, Helsinki.

[7] Sandberg, D. (2005) Radially Sawn Timber-The Primwood Method for Improved Properties. Holz als Roh- und Werkstoff, 63, 94-101. http://dx.doi.org/10.1007/s00107-004-0531-9

[8] Sandberg, D. and Söderström, O. (2006) Crack Formation Due to Weathering of Radial and Tangential Sections of Pine and Spruce. Wood Material Science and Engineering, 1, 12-20. http://dx.doi.org/10.1080/17480270600644407

[9] Sandberg, D. (1999) Weathering of Radial and Tangential Wood Surfaces of Pine and Spruce. Holzforschung, 53, 355-364. http://dx.doi.org/10.1515/HF.1999.059

[10] Sandberg, D. (2005) Distortion and Visible Crack Formation in Green and Seasoned Timber: Influence of Annual Ring Orientation in the Cross Section. Holz als Roh- und Werkstoff, 63, 11-18. http://dx.doi.org/10.1007/s00107-004-0546-2

[11] Hoadley, R.B. (1989) Understanding Wood. A Craftsman's Guide to Wood Technology. 6th Printing, The Taunton Press, Newtown.

[12] Sandberg, D. (1995) Ståendeårsringar hos furu (Pinussilvestris L.) och gran (Piceaabies Karst) (Standing Year Rings in Pine (Pinussilvestris L.) and Spruce (Piceaabies Karst). TRITA-TRÄR-95-13.

[13] Grönlund, A. (1987) Yield and Production Technology of Trapeze Sawing Compared to Various Other Sawing Methods. Utbyteochproduktionsteknik vid trapetssågningjämfört med olikaandrasågmetoder. PhD Thesis, Royal Institute of Technology, Stockholm.

[14] Cown, D.J., McConchie, D.L. and Kimberley, M.O. (1988) Sawing Methods for Pinusradiata Pruned Logs-An Indicative Study. New Zealand Journal of Forestry, 13, 345-358.

[15] Grekin, M. and Verkasalo, E. (2010) Variations in Basic Density, Shrinkage and Shrinkage Anisotropy of Scots Pine Wood from Mature Mineral Soils Stands in Finland and Sweden. Baltic Forestry, 16, 113-125.

[16] Hautamäki, S., Kilpeläinen, H., Kannisto, K., Wall, T. and Verkasalo, E. (2010) Factors Affecting the Appearance Quality and Visual Strength Grade Distributions of Scots Pine and Norway Spruce Sawn Timber in Finland and North-Western Russia. Baltic Forestry, 16, 217-234.

[17] Mehtälä, T. (2006) Clarification of Factors Affecting Cracking of Wood Surface. Master thesis, Helsinki University of Technology, Department of Mechanical Wood Technology, Espoo. 
Submit or recommend next manuscript to SCIRP and we will provide best service for you:

Accepting pre-submission inquiries through Email, Facebook, LinkedIn, Twitter, etc. A wide selection of journals (inclusive of 9 subjects, more than 200 journals)

Providing 24-hour high-quality service

User-friendly online submission system

Fair and swift peer-review system

Efficient typesetting and proofreading procedure

Display of the result of downloads and visits, as well as the number of cited articles

Maximum dissemination of your research work

Submit your manuscript at: http://papersubmission.scirp.org/ 